\title{
Urdimento
}

Revista de Estudos em Artes Cênicas

E-ISSN: 2358.6958

\section{Os Colégios de Aplicação no sistema educacional brasileiro: contexto de criação e reverberações no ensino de Teatro}

William Fernandes Molina

Vera Lúcia Bertoni dos Santos

\section{Para citar este artigo:}

MOLINA, William Fernandes e SANTOS, Vera Lúcia

Bertoni dos. Os Colégios de Aplicação no sistema educacional brasileiro: contexto de criação e reverberações no ensino de Teatro. Urdimento, Florianópolis, v. 2, n. 38, ago./set. 2020.

DOI: http:/dx.doi.org/10.5965/14145731023820200042

Este artigo passou pelo Plagiarism Detection Software | iThenticate 
Os Colégios de Aplicação no sistema educacional brasileiro: contexto de criação e reverberações no ensino de Teatro

William Fernandes Molina ${ }^{1}$

Vera Lúcia Bertoni dos Santos²

\begin{abstract}
Resumo
O artigo reflete sobre as condições de emergência dos Colégios de Aplicação (CAPs) no país, a partir de um apanhado histórico de sua criação e do seu papel na formação docente e discente. Relaciona-se sua fundação a transformações educacionais almejadas nas primeiras décadas do século XX. Os CAPs são idealizados como campo de prática e pesquisa docente para estudantes dos cursos de Didática, o que lhes confere natureza diferenciada e, em certa medida, elitista. O texto encerra com uma reflexão sobre a realidade do CAp/UFRGS, no que se refere ao ensino de Teatro, evidenciando condições favoráveis ao trabalho pedagógico e à aprendizagem de conhecimentos relacionados a essa área artística.
\end{abstract}

Palavras-chave: Educação básica. Universidade pública. Formação de professores. Teatro na escola.

The Application Schools in the brazilian educational system: context of creation and reverberations in the teaching of Theater

\begin{abstract}
The article reflects on the emergency conditions of the Application Schools (CAPs) in Brazil, based on a brief historical overview of the creation of these educational institutions and their role in the training of students and teachers. The text links the creation of CAPs to significant transformations envisaged in the first decades of the 20th century. CAPs are idealized as a field of teaching practice and research for students of Didactics courses, which gives them a differentiated and, to a certain extent, elitist nature. The text ends with a reflection on the reality of the CAP of the Federal University of Rio Grande do Sul (UFRGS), with regard to the teaching of Theater, showing favorable conditions for pedagogical work and the learning of knowledge related to this artistic area.
\end{abstract}

Keywords: Basic education. Public university. Teacher training. Theater at school.

${ }^{1}$ Professor de Teatro no Colégio de Aplicação da Universidade Federal do Rio Grande do Sul (CAp/UFRGS). Doutorando em Artes Cênicas pelo Programa de Pós-Graduação em Artes Cênicas da Universidade Federal do Rio Grande do Sul (PPGAC/UFRGS).wfmolina87@gmail.com

2 Profa. Dra. Associada e pesquisadora vinculada ao Programa de Pós-Graduação em Artes Cênicas (PPGAC) e ao Departamento de Arte Dramática (DAD) do Instituto de Artes da Universidade Federal do Rio Grande do Sul (UFRGS). Atriz de teatro. bertonica@gmail.com 
Las Escuelas de Aplicación en el sistema educativo brasileño: contexto de creación y reverberaciones en la enseñanza del Teatro

\section{Resumen}

El artículo reflexiona sobre las condiciones de emergencia de los Escuelas de Aplicación (CAPs) en el país, en base a una descripción histórica de su creación y su papel en la formación de docentes y estudiantes. Su fundamento está relacionado con las transformaciones educativas previstas en las primeras décadas del siglo XX. Los CAP están idealizados como un campo de práctica docente e investigación para estudiantes de cursos de Didáctica, lo que les da una naturaleza diferente y, en cierta medida, elitista. El texto termina con una reflexión sobre la realidad de CAp/UFRGS, con respecto a la enseñanza del teatro, que muestra condiciones favorables para el trabajo pedagógico y el aprendizaje del conocimiento relacionado con esta área artística.

Palabras clave: Educación básica. Universidad publica. Formación de profesores. Teatro escolar. 
Os estudos que motivam a escrita deste texto constituem parte fundamental do arcabouço teórico de uma investigação sobre o ensino da disciplina de ArtesTeatro no Colégio de Aplicação (CAp) da Universidade Federal do Rio Grande do Sul (UFRGS), que se propõe a conhecer mais profundamente e contextualizar de forma mais ampla a realidade dos Colégios de Aplicação brasileiros, desde a sua criação, levando em conta o papel atribuído a essas instituições na educação de jovens estudantes e na formação de professores para a Educação Básica.

Tendo por base empírica um levantamento histórico obtido mediante análise documental e entrevistas com docentes atuantes no interstício considerado intermediário entre as práticas inaugurais de inserção do Teatro no CAp/UFRGS e as propostas em vigor na atualidade, a investigação enfoca as relações de continuidade, ruptura e superação evidenciadas ao longo do tempo, na busca de refletir sobre as bases do trabalho pedagógico desenvolvido atualmente. A busca por compreender o contexto e fundação da escola norteou a etapa inicial do estudo, pois as características identitárias da instituição tendem a definir, ou a influenciar os modelos e práticas que orientaram o ensino de Teatro que nela se desenvolve.

Na intenção de refletir sobre o processo que culmina na criação dos CAPs, escolas de natureza diferenciada das demais instituições que compõem a Educação Básica, realiza-se um breve panorama da conjuntura brasileira das primeiras décadas do século XX, considerando os movimentos significativos que propuseram mudanças na educação nacional, e apresenta-se o histórico de criação das Faculdades de Filosofia Federais, instituições nas quais os chamados Ginásios de Aplicação se tornaram campo preferencial de experiência docente aos estudantes do Curso de Didática.

O texto principia por uma caracterização objetiva dos CAPs, realizada com base nas disposições da Portaria 959 (Brasil, 2013), documento que rege essas instituições de ensino público, na busca de evidenciar alguns aspectos do contexto sociopolítico e econômico brasileiro do início do século XX, que fomentam a busca por um novo modelo de sistema educacional nacional, no qual a criação dos CAPs 
é compreendida como uma iniciativa representativa de avanços determinantes do modo de se pensar a respeito da formação docente dos professores brasileiros.

O final do texto propõe uma reflexão sobre a ideia de escola "de excelência", difundida no imaginário da sociedade brasileira em relação aos CAPs desde a sua criação até os nossos dias, na qual são problematizados os porquês dessa caracterização e as implicações que dela se originam, na busca de abranger o papel que essas instituições cumprem no sistema de ensino brasileiro e de compreender de que modo a sua estrutura e forma de organização podem colaborar na luta por uma educação nacional mais democrática, diversa e, de fato, inclusiva. Além disso, através da percepção de docentes da instituição que vivenciaram um período na escola em que o acesso ao colégio se tornou universal por meio de sorteio público, evidencia-se a transformação realizada no Ensino de Teatro no CAp/UFRGS no que diz respeito, sobretudo, à reformulação curricular.

\section{Definições e diretrizes para uma escola diferenciada}

Conforme consta na portaria Portaria 959 (BRASIL, 2013), que estabelece as diretrizes e normas gerais para o funcionamento dos CAPs, essas instituições constituem unidades de educação vinculadas, mantidas e administradas por Universidades Federais, integrando o sistema federal de ensino; e são, por definição, "unidades de educação básica que têm como finalidade desenvolver, de forma indissociável, atividades de ensino, pesquisa e extensão com foco nas inovações pedagógicas e na formação docente." (Brasil, 2013).

Regimentalmente são determinadas quatro diretrizes a serem seguidas pelos CAPs. As duas primeiras diretrizes definem a oferta gratuita das suas vagas discentes e a igualdade de condições de acesso e permanência dos estudantes nas escolas. A terceira diretriz determina uma das características fundamentais dessas escolas, que interessa especialmente a este trabalho, tal seja: a sua integração com os cursos de licenciatura das universidades, o que confere aos CAPs um papel de corresponsabilidade pela formação docente realizada nessas instituições, mais evidente nos estágios curriculares oferecidos nesses cursos. E a 
quarta das diretrizes apontadas pela portaria reforça o caráter de formação de professores, a ser desenvolvido pelas unidades universitárias mediante participação institucional em programas de formação docente, a exemplo do que atualmente ocorre com o Programa Institucional de Bolsas de Iniciação à Docência $(\mathrm{PIBID})^{3}$.

De acordo com a Portaria 959 (Brasil, 2013), são dezessete os CAPs no Brasil integrantes de instituições federais de ensino. Cada um deles tem suas características particulares em relação ao período de fundação, à oferta de ensino, à forma de ingresso de estudantes, ao número de servidores docentes, dentre outros aspectos. Segundo a publicação do Ministério da Educação e do Desporto, intitulada Repensando as Escolas de Aplicação (1993), desde a sua fundação, os CAPs mostram-se campos próprios para experimentar novos modelos de metodologia, didática e de organização escolar, o que faz com que se diferenciem cada vez mais de outras escolas.

Na esteira de transformações na estrutura educacional brasileira

A criação dos CAPs no Brasil ocorre em função de significativas transformações no sistema de educação nacional, processadas desde a década de 1920, que têm, entre os seus marcos, a publicação do Manifesto dos Pioneiros da Educação Nova, documento elaborado no ano de 1932, por intelectuais, escritores e educadores brasileiros, em reflexo da necessidade de organização de um sistema escolar nacional democrático. Todavia, antes mesmo da divulgação dos ideais educacionais dos pioneiros, alterações que vinham sendo sentidas na matriz produtiva nacional desde o início do século principiaram transformações no pensamento e nos objetivos da educação no país, principalmente ao final da

\footnotetext{
${ }^{3}$ O PIBID constitui uma iniciativa implementada em 2007, pela Coordenação Geral de Desenvolvimento de Conteúdos Curriculares e de Modelos Experimentais da Diretoria de Educação Básica (DEB) Presencial, da Coordenação de Aperfeiçoamento de Pessoal (CAPES) de Nível Superior do Ministério da Educação (MEC), que visa à integração do Ensino Superior e da Educação Básica Por meio da participação no Projeto, estudantes dos cursos de Licenciatura de diferentes áreas do conhecimento interagem com professores do Ensino Superior e das escolas de Ensino Fundamental e Médio e têm contato com a realidade das instituições da Rede Pública de Educação (Santos, 2012a).
} 
segunda década, devido à guinada em favor da ampliação da industrialização nacional, influenciada pela crise econômica então deflagrada.

No Brasil das décadas de 1920 e 1930 ocorre uma importante alteração na matriz produtiva nacional, antes oligárquica, que passa a ser industrial (Frangella, 2000), exigindo do Estado uma revisão da sua atuação, principalmente no que diz respeito à estrutura elitista da educação, e gerando a necessidade de se repensar o sistema educacional como um todo.

Nas primeiras décadas do século XX, a preocupação com a promoção do acesso à educação a todas as parcelas da sociedade é praticamente inexistente, pois não interessa às classes que detêm o poder educar a população trabalhadora ${ }^{4}$. A pesquisadora Helena Bomeny menciona que, naquele período,

Educação básica não era, de fato, um problema ou uma questão que sensibilizasse a elite brasileira. Por isso é que podemos afirmar que o estranhamento e a perplexidade com os quase $80 \%$ de analfabetos são uma reação pública posterior ao final do século XIX. Em uma sociedade basicamente rural, - mais de $80 \%$ da população -, comandada pelos grupos oligárquicos, com precários sistemas de comunicação, a demanda social de educação era também muito. (Bomeny, 2003, p. 3).

Entretanto, a necessária adequação do país às demandas da industrialização obriga o Estado a repensar a sua organização. E reestruturar o sistema educacional passa a ser necessário e inevitável. Conforme Joycimar Lemos Barcellos (2015), no período da Primeira Guerra Mundial (1914-1918) e nos anos subsequentes, o país teve de realizar uma guinada industrial, diversificando sua produção, pois a importação de produtos já não acontecia da mesma forma que antes em função dos impactos causados pela guerra na economia mundial. Naquele contexto, novas formas de divisão social do trabalho tiveram de ser organizadas, resultando na transformação das estruturas da sociedade.

Segundo Barcellos (2015, p.796), a "classe dominante brasileira passou a considerar o proletariado como elemento integrante do jogo político", visto que,

${ }^{4}$ Dados do Recenseamento realizado em 1906 no Brasil apresentam uma média nacional de analfabetismo na ordem dos $74,6 \%$. 
nacional e internacionalmente, ocorriam movimentos populares que exigiam melhores condições sociais.

O crescente aumento da população brasileira também traria novas necessidades e problemáticas para o cotidiano. De modo que, repensar as formas de organização e de acesso à educação torna-se uma meta a ser assumida por parte do Estado e da sociedade. Colaboraram ainda para a mudança no sistema de educação brasileiro as reformas educacionais, feitas pouco a pouco nos estados da federação, responsáveis por impulsionar grandes movimentos para a transformação do pensamento e dos objetivos da educação brasileira.

Na década de 1930, o ministro da Educação e Saúde Pública, Francisco Campos, implementa uma Reforma educacional no país, que tinha por objetivo estruturar o sistema de ensino brasileiro (Frangella, 2000). Um de seus atos é a emissão do Decreto n. 19.851, de 11 de abril de 1931 (Brasil, 1931), que estabelece o sistema universitário, definindo-o como a forma de organização didáticoadministrativa das instituições de ensino superior nacionais. Desde então, o ensino superior no Brasil passa a obedecer, preferencialmente, ao sistema universitário.

Em meados da década de 1940, a administração pública nacional vivencia um período de forte conservadorismo. A presidência do Brasil, ocupada pelo militar Eurico Gaspar Dutra, que governa entre os anos de 1946 e 1951, adota diversas medidas de restrição e cerceamento, dentre elas, a proibição dos jogos e o fechamento dos cassinos, o congelamento do salário mínimo, a repressão ao movimento operário e o fechamento da Confederação Geral dos Trabalhadores (Benites, 2006). Além disso, o então presidente se alinha às políticas norteamericanas, rompendo relações diplomáticas com a União Soviética e decretando a ilegalidade do Partido Comunista do Brasil.

Recém-saído do período denominado historicamente como Estado Novo, sob a presidência de Getúlio Vargas, mas ainda sob um regime de governo conservador, o Brasil vivencia alguns avanços que apontam para uma possível redemocratização. Transformações significativas no pensamento político da administração pública são efetuadas, promovendo modificações nos rumos da 
educação nacional. Uma nova Constituição Federal é publicada em 1946, trazendo uma série de determinações que indicam relativo progresso.

Com a nova constituição, são tomadas importantes medidas no sentido da restauração democrática e da liberdade de expressão e organização, tais como, o restabelecimento da autonomia dos estados e municípios, a ampliação da participação política da população, com a extensão do direito de voto às mulheres, e a extinção da pena de morte (Benites, 2006).

Se na política e na economia grandes mudanças eram sentidas, no que tange à educação nacional ocorrem transformações no pensamento e posicionamento da administração, por meio de movimentos realizados na época. De acordo com Frangella (2000), na década de 1920 já se realizam reformas no ensino promovidas por alguns estados brasileiros, que se mostraram precursoras das lutas que viriam a ser travadas entre o movimento renovador, inspirado por ideais da Pedagogia Nova, e um grupo ligado à Igreja Católica, ambos querendo promover, ao seu modo, mudanças no sistema educacional brasileiro.

Se, por um lado, o movimento renovador agiria em defesa da escola pública, obrigatória, laica e gratuita, por outro, os católicos defenderiam a integração dos preceitos religiosos aos currículos escolares. Segundo Barcelos (2015), a laicidade do Estado, defendida pelos pioneiros, seria um elemento político a somar forças ao movimento renovador da educação.

No ano de 1931, a publicação do Decreto no 19.941, pelo ministro Francisco Campos, sancionado por Getúlio Vargas, então chefe do governo Provisório, acirra as críticas dos pioneiros à forma de como o sistema educacional do país vem se organizando. De acordo com o decreto (Brasil, 1931), o ensino religioso deveria ser reintroduzido nos estabelecimentos de instrução primária, secundária e normal, com programas elaborados pelos ministros dos respectivos cultos religiosos, numa perspectiva de controle e inspeção sistemática da doutrina e da moral dos professores.

Impulsionadas pelo movimento Escola Nova, difundido no meio educacional brasileiro, as críticas às medidas conservadoras ganham força nas primeiras 
décadas do século XX, propondo uma renovação do ensino, até então pautado em modelos de educação clássicos e humanistas. Tomaz Tadeu da Silva (2015) referese à modificação no currículo proposta pelo modelo considerado progressista do movimento Escola Nova como reação ao que vigorava até então. Segundo Silva (2015), o modelo de currículo dominante era o clássico, humanista, estabelecido na educação da Idade Média e no Renascimento, que tinha por objetivo apresentar aos estudantes as grandes obras literárias e artísticas da Antiguidade Clássica, sob as formas do trivium (gramática, retórica, dialética) e do quadrivium (astronomia, geometria, música, aritmética).

Um dos expoentes do movimento Escola Nova é o pedagogo e filósofo norteamericano John Dewey (1859-1952), para quem “a educação não era tanto uma preparação para a vida ocupacional adulta, como um local de vivência e prática direta de princípios democráticos" (Silva, 2015, p.23). Outros pensadores da educação, a exemplo de Montessori e Claparède, também se relacionam a esse movimento, que propõe transformações pedagógicas ao sistema educacional, colocando o indivíduo (ou a criança) como elemento central no processo educativo em todos os níveis e campos de conhecimento (Santos, 2012b).

No ano de 1932, em meio à efervescência das discussões sobre a educação brasileira, é divulgado o Manifesto dos Pioneiros da Educação Nova, assinado por um grupo de intelectuais do meio educacional. O documento parte de uma forte crítica ao governo, apontando as fragilidades do regime republicano, que, nos últimos 43 anos, não foi capaz de criar um sistema de organização escolar correspondente às necessidades da modernidade e do país. A reformulação e renovação da educação nacional proposta a partir daí passa a reivindicar o ensino público laico, gratuito e obrigatório, e a chamada coeducação, que compreende meninos e meninas compartilhando o mesmo ambiente escolar.

A defesa do Manifesto era para que a educação fosse um direito de todos os indivíduos, independentemente das suas condições sociais e econômicas. A garantia de oferecimento das mesmas oportunidades de educação a todos os brasileiros estaria intimamente relacionada aos propósitos de democratização da escola. 
De acordo com Frangella (2000), a educação brasileira da década de 1940 centrava-se mais na instrução do que na formação dos sujeitos, cabendo às elites uma educação diferenciada do restante da população. Com o Manifesto, os intelectuais da educação nacional decidem apresentar ao governo a necessidade de modificar a estrutura de ensino vigente no país, expressando textualmente o desejo por uma nova educação, que deveria servir aos interesses do indivíduo e não ao das classes.

As palavras do educador Fernando de Azevedo, redator do Manifesto, atestam esses aspectos:

A escola tradicional, instalada para uma concepção burguesa, vinha mantendo o indivíduo na sua autonomia isolada e estéril, resultante da doutrina do individualismo libertário, que teve, aliás, seu papel na formação das democracias e sem cujo assalto não se teriam quebrado os quadros rígidos da vida social. A escola socializada, reconstituída sobre a base da atividade e da produção, em que se considera o trabalho como a melhor maneira de estudar a realidade em geral (aquisição ativa da cultura) e a melhor maneira de estudar o trabalho em si mesmo, como fundamento da sociedade humana, se organizou para remontar a corrente e restabelecer, entre os homens, o espírito de disciplina, solidariedade e cooperação, por uma profunda obra social que ultrapassa largamente o quadro estreito dos interesses de classes. (Azevedo, 1932 apud Brasil, 2010, p.40-41).

Segundo Benites (2006), o propósito essencial do movimento definido por Dewey como Escola Nova era transformar as escolas em pequenas comunidades, destituindo a educação da função de mera transmissora de conhecimentos e vinculando a escola à função social e aos ideais de solidariedade, serviço comunitário e cooperação. Nas novas escolas, o trabalho em comunidade seria estimulado, o que envolveria abdicar do silêncio nas aulas e estimular o diálogo entre os estudantes. A partir da ideia de relacionar a escola e os conhecimentos com a vida e com a experiência dos alunos, a nova escola tinha por intuito trabalhar conteúdos de forma crítica e promover a escuta às diferentes vozes dos indivíduos da classe. (Benites, 2006).

A função do professor, nessa nova visão de escola, também se altera. Ele já não é mais figura central do processo educacional, mas se torna um orientador do percurso dos estudantes, tomados em suas individualidades. São métodos ativos 
que orientam a ação dos professores, contrários à educação por modelos, que impunha, reproduzia e perpetuava valores da sociedade, oferecendo uma integração dos alunos na sociedade de forma passiva.

Segundo o Manifesto, o educador necessita de formação cultural diversificada, pois "ele deve ter o conhecimento dos homens e da sociedade em cada uma de suas fases, para perceber, além do aparente e do efêmero, 'o jogo poderoso das grandes leis que dominam a evolução social'” (Brasil, 2010, p.34-35). Um saber diversificado auxiliaria na compreensão por parte dos professores da posição da escola na sociedade e da função que representa. A posição de pesquisador de suas próprias ações também é exposta no documento como papel dos educadores.

Se tem essa cultura geral, que the permite organizar uma doutrina de vida e ampliar o seu horizonte mental, poderá ver o problema educacional em conjunto, de um ponto de vista mais largo, para subordinar o problema pedagógico ou dos métodos ao problema filosófico ou dos fins da educação; se tem um espírito científico, empregará os métodos comuns a todo gênero de investigação científica, podendo recorrer a técnicas mais ou menos elaboradas e dominar a situação, realizando experiências e medindo os resultados de toda e qualquer modificação nos processos e nas técnicas, que se desenvolveram sob o impulso dos trabalhos científicos na administração dos serviços escolares. (Azevedo, 1932 apud Brasil, 2010, p. 35).

Verifica-se, portanto, o desejo por uma formação qualificada dos professores, a fim de que os ideais presentes no Manifesto pudessem ser efetivados na sua prática em sala de aula. De acordo com Frangella (2000), a busca por novos professores e pela profissionalização da função docente é reflexo do debate travado em torno das questões educacionais desde a década de 1920. O desejo por um país industrializado e urbanizado, segundo a autora, não poderia estar dissociado da promoção de transformações nas atividades educacionais, a começar por uma escola que atendesse a uma parcela maior da sociedade.

Nesse contexto político, o debate sobre a necessidade de qualificação docente amplia-se largamente, envolvendo especialistas e setores governamentais, até culminar na criação, no âmbito federal, de instituições de 
ensino primário e secundário nas quais os estudantes dos cursos superiores de Didática ${ }^{5}$ pudessem exercitar a docência. Assim, a partir de 12 de março de 1946, pelo Decreto no 9.053 da presidência da república, fica estabelecida a obrigatoriedade da manutenção dos chamados "ginásios de aplicação" nas dependências das Faculdades de Filosofia. Conforme os termos do Decreto:

Art. 10 As Faculdades de Filosofia federais, reconhecidas ou autorizadas a funcionar no território nacional, ficam obrigadas a manter um ginásio de aplicação destinado à prática docente dos alunos matriculados no curso de didática. (Brasil, 1946).

Depois da publicação do Decreto, as faculdades deveriam assumir o compromisso de cumprir suas determinações no prazo de um ano.

Conforme o Decreto 9.053, esses ginásios deveriam funcionar no prédio sede da faculdade, ou num espaço físico próximo a ela. A direção e a responsabilidade pelos ginásios de aplicação ficariam a cargo de catedráticos de Didática geral de cada faculdade. Nos cursos ginasiais, os alunos dos cursos de Didática das faculdades de Filosofia teriam de assumir as diversas cadeiras em cada turno, sob orientação do catedrático de Didática geral e dos assistentes de didática especializada.

\section{Dos Ginásios aos Colégios de Aplicação}

Os chamados Ginásios de Aplicação começam a ser concebidos e estabelecidos nas faculdades federais a partir do final da década de 1940, estendendo-se pelas décadas posteriores, com a finalidade de se constituírem campo de atuação para os estudantes do curso de Didática das Faculdades de Filosofia. O primeiro dos Colégios de Aplicação é criado em 1948, na Universidade Federal do Rio de Janeiro, sendo chamado, à época, de Colégio de Demonstração. Segundo Frangella,

${ }^{5}$ O Curso de Didática passa a ser um curso ordinário, que compõe uma seção especial entre as seções fundamentais estabelecidas pelo Decreto-lei № 1.190 de 04 de abril de 1939 (Brasil, 1939) como constituintes das Faculdades de Filosofia nacionais. 
A ideia de um colégio de demonstração nasce no interior das Faculdades de Filosofia tendo em vista a necessidade desta no que refere-se às aulas de prática de ensino ali ministradas aos futuros professores do ensino secundário. Instituições de caráter semelhante já funcionavam na Alemanha e Estados Unidos. A criação do CAp se dá entrelaçada à preocupação com formação de professores e remete aos objetivos estabelecidos no Estatuto das Universidades Brasileiras que é, além da formação e habilitação ao exercício de atividades que requeiram preparo técnico científico, estimular a investigação científica. O colégio de aplicação aponta também para o fomento de uma tradição de pesquisa educacional. (Frangella, 2000, s.p.).

O início das tratativas que dão origem às escolas de Educação Básica estabelecidas nas faculdades de Filosofia tem como um dos pontos de partida a constatação cada vez mais presente na época, de acordo com Ernesto de Souza Campos $^{6}$ (1957), de que era necessário investir na preparação dos estudantes ingressantes em cursos superiores. Segundo ele, era preciso preparar os professores que atuariam junto aos estudantes secundaristas para que, com a formação devida, estivessem preparados a prestar as provas de ingresso nas escolas superiores.

Em relato publicado em artigo da Revista Brasileira de Estudos Pedagógicos do ano de 1957, Campos revela, de forma crítica, algumas das características das aulas de ensino secundário ministradas nas primeiras décadas do século XX no Brasil:

No que tange aos estudos de segundo grau, estavam estes, como todos sabem, sobrecarregados de disciplinas, ministradas através de programas extensos e impraticáveis, dos quais apenas alguns pontos eram versados em aulas e sem a competente objetivação. E não passavam de aulas de repetição livresca, ministradas apressadamente, porque os mestres, mal remunerados, eram obrigados a correr de um lado para o outro, dando oito a dez aulas diárias, a fim de conseguir salário mesmo assim modestíssimo. O equipamento era inexistente ou precário. No horário escolar nem se cogitava de tempo para aulas práticas. Aulas teóricas maciças sucediam-se durante todo o período escolar. Os mestres, embora alguns fossem realmente dedicados a seu mister, eram autodidatas ou eram oriundos de outros setores de atividade e que naquele magistério procuravam apenas um reforço para sua situação financeira. Ficavam, assim, os alunos em posição passiva, ouvindo, ouvindo, ouvindo, sem participação ativa nos trabalhos. Esta era a regra.

${ }^{6}$ Ministro da Educação e Saúde Pública em 1946 no governo de Eurico Gaspar Dutra. Foi professor emérito da Faculdade de Medicina da Universidade de São Paulo (USP). 
Seria inútil prolongar tais comentários em assunto assaz conhecido. (Campos, 1957, p. 234).

Cabe aqui considerar, tendo por base observações assistemáticas e pesquisas acadêmicas sobre o cotidiano da Educação Básica, que, apesar de se referir a metodologias e procedimentos de ensino empregados no início do século passado, a descrição feita por Campos parece fazer sentido, em diversos pontos, se comparada ao ensino escolar processado em muitas escolas brasileiras do início do século XXI. Do mesmo modo, a rotina de trabalho descrita não parece muito diferente da rotina vivida por professores hoje em dia. Já em relação ao pertencimento de professores a outras áreas do saber, pode-se pensar especificamente sobre os professores do componente curricular Artes na escola no contexto brasileiro, dos quais, segundo o levantamento da ONG Todos pela Educação para o Observatório do Plano Nacional da Educação (PNE), com dados do Censo Escolar de 2013, uma parcela de 92,3\% não possui habilitação específica.

Reitores da Universidade do Brasil e da Pontifícia Universidade Católica do Rio de Janeiro são consultados, segundo Campos (1957), para conferirem seu apoio à iniciativa da fundação de Ginásios de Aplicação nas Faculdades de Filosofia federais. E o Decreto-lei federal no 9.053, de 12 de março de 1946, é, então, assinado, passando a definir a obrigatoriedade da existência dos Ginásios de Aplicação nessas instituições.

De início, de acordo com Campos (1957), define-se que o ensino nos cursos de aplicação seria limitado a apenas ao ciclo o ginasial7?. O prazo de um ano para que as faculdades atendessem a essa determinação também influenciaria na definição de apenas um dos ciclos. No entanto, como aponta Minoru Martins Kinpara (1997), as primeiras escolas que começam a funcionar de acordo com o referido decreto não são os Ginásios de Aplicação, mas os Colégios, pelo fato de ministrarem não apenas o ensino ginasial, mas também o colegial.

Correspondia ao que hoje são os anos finais do Ensino Fundamental (6o ao 9o ano). O ciclo colegial (correspondente ao Ensino Médio) não foi instituído como campo de atuação para os cursos de aplicação conforme o decreto. Além dos dois, existia o Primário (correspondente aos anos iniciais do Ensino Fundamental). 
Um dos maiores objetivos para a criação dos Colégios de Aplicação foi possibilitar a prática docente nos cursos de Didática oferecidos pelas faculdades - função tomada como essencial nessas instituições. Segundo Campos,

\begin{abstract}
A didática, dispensável para os que não se destinam ao magistério secundário, deve ser obrigatória, sob modelos adequados, para os que visam ao professorado naquele grau de ensino. Mas a didática teórica, apenas ditada por ensinamentos de pedra e giz, pouco valor prático apresenta. Para a plenitude de sua eficiência deve a didática se operar ao vivo, sob o calor da prática de ensino em estabelecimentos que, para o caso, representam análoga função que tem o hospital na formação do médico. (Campos, 1957, p.237, grifos do autor).
\end{abstract}

No Decreto-lei 9.092, definiu-se que "Para obter o diploma de licenciado, os alunos do quarto ano receberão formação didática, teórica e prática, no ginásio de aplicação e serão obrigados a um curso de psicologia aplicada à educação" (BRASIL, 1946). A respeito das intenções em relação à criação dos ginásios de aplicação, Campos considera:

Em suma, criando o Ginásio de Aplicação, desejamos:

1 - - Proporcionar a prática didática em casa de ensino apropriada, dotada de todos os recursos para tal finalidade.

$2^{\circ}$ - Instituir uma casa de ensino modelar para estímulo e emulação de outras do mesmo grau.

$3^{\circ}$ - Abrir, sob a égide da Faculdade de Filosofia, um campo experimental palpitante e evolutivo.

Tudo isso vale muito mais do que qualquer reforma de ensino, em que o mecanismo fique girando com as mesmas rodas, apenas mudadas de lugar, ou então ampliadas ou reduzidas em suas proporções, sem os ditames de um campo experimental ativo e real. (Campos, 1957, p.238).

Os primeiros Colégios de Aplicação criados no Brasil foram os da Faculdade Nacional de Filosofia do Rio de Janeiro, em 1948, e da Faculdade de Filosofia da Universidade Federal da Bahia, em 1949 (Kinpara, 1997). No final da década de 1940 e durante as décadas de 1950 e 1960, colégios do mesmo tipo são fundados em outras instituições federais. Nas décadas seguintes, outros CAPs vão sendo criados, com intuito de auxiliar na formação dos profissionais docentes do Ensino Superior. 
Concebidos como campo preferencial para a atuação dos professores em formação nos cursos de Didática das Faculdades de Filosofia e Letras, com vistas a propiciar a experimentação de novas metodologias de ensino, os inicialmente denominados Ginásios de Aplicação passam por algumas alterações importantes, realizadas no ano de 1962 (Parecer 292/62 do Conselho Federal de Educação), até serem considerados "centros de experimentação e demonstração". Conforme o Parecer, "as práticas de ensino deveriam ser realizadas nas próprias escolas da comunidade" (BRASIL, 1993, p.12), o que torna as escolas das comunidades campo preferencial para aplicação das teorias estudadas pelos licenciandos nos cursos universitários, cabendo aos CAPs a função de experimentação e demonstração.

A pesquisadora Evelline Soares Correia (2017) reflete sobre o papel assumido pelos CAPs ao longo dos anos, chamando atenção para o desequilíbrio da atuação dessas instituições no que se refere às funções de experimentação, que, segundo ela, passaram a ser relegadas a um segundo plano, em favor das práticas de estágio de docência aos licenciandos dos cursos universitários. Segundo Correia, a experimentação refere-se à investigação de soluções a problemas e dúvidas encontrados nas situações da prática profissional, relacionando-se, portanto, à pesquisa. Já o estágio curricular se apresenta como um treinamento para a prática profissional dos futuros professores. Assim, na medida em que a experimentação foi sendo desvalorizada nas práticas de formação docente realizadas nos CAPs, a discussão e a reflexão sobre a própria prática pedagógica nos estágios, tidas como funções dessas instituições, foram deixando de acontecer. (Correia, 2017).

\section{A busca por uma educação de excelência}

Desde sua criação, os Colégios de Aplicação integram as Universidades, constituindo-se como tais. Não são meramente "anexos", ou "apêndices", que a elas se acrescentam, mas Unidades consolidadas institucionalmente, que aliam o ensino na Educação Básica à formação de professores. Essa função primordial faz parte da natureza dessas instituições, que têm foco no ensino, na pesquisa e na extensão universitária, fator que as diferencia da grande maioria das escolas de 
Educação Básica, públicas ou privadas. O fato de constituir-se como Universidade, inevitavelmente, confere aos CAPs, em certa medida, o status que as instituições de Ensino Superior brasileiras carregam desde seu princípio, e que, por força das desigualdades sociais que se acirram no país, ainda perdura: o de ser um "lugar para poucos".

Fávero (2006) problematiza as origens da Universidade brasileira,

[...] criada não para atender às necessidades fundamentais da realidade da qual era e é parte, mas pensada e aceita como um bem cultural oferecido a minorias, sem uma definição clara no sentido de que, por suas próprias funções, deveria se constituir em espaço de investigação científica e de produção de conhecimento. Produção essa que deveria procurar responder às necessidades sociais mais amplas e ter como preocupação tornar-se expressão do real, compreendida como característica do conhecimento científico, mas sem a falácia de respostas prontas e acabadas. (Fávero, 2006, p.19).

Tratando-se da formação de professores, um dos objetivos principais dos CAPs e que, na década de 1940, justificaram sua criação, é preciso atentar para o fato de que não são todos os docentes (estudantes das Licenciaturas ou já atuantes em redes de ensino) que conseguem realizar a sua qualificação nos Colégios de Aplicação. Frangella (2000) observa uma contradição no discurso e na prática dessas instituições, pois, ao mesmo tempo em que defendem que a prática continuada em educação é indispensável à melhoria de sua qualidade, indicam que é na Universidade que uma formação qualificada acontecerá. No entanto, em nosso país, o acesso à Universidade é bastante restrito. Conforme a pesquisadora, fazer da Universidade o local privilegiado para o processo de formação continuada dos docentes impossibilita que muitos professores possam realizá-la. Assim, permanecem resquícios de uma educação elitizada nesse sistema.

Se, por um lado, a natureza dos CAPs faz com que gozem de um status diferenciado, em relação às demais escolas de Educação Básica, por outro, esses colégios estão sujeitos ao rigor das normativas (práticas de planejamento, avaliação e controle) da Universidade, bem como aos jogos de poder/saber que se constituem nesse espaço (questões de pertencimento e afirmação do território 
que ocupam). A organização funcional universitária vigente nos CAPs, por exemplo, pode interferir na realização de atividades que levem à construção de novos conhecimentos e ao trabalho integrado de docentes. Fávero (2006) menciona que a departamentalização (organização das áreas do conhecimento em Departamentos) encontra resistências no ambiente universitário e, por vezes, impede o desenvolvimento de práticas inovadoras. Segundo a autora, "o departamento, frequentemente, [é] um espaço de alocação burocráticoadministrativa de professores, tornando-se, em alguns casos, elemento limitador e até inibidor de um trabalho de produção de conhecimento coletivo." (Fávero, 2006, p.34).

Outro fator que influencia diretamente na identidade dos CAPs e que os conforma é a busca por excelência e inovação no ensino, valores presentes na descrição das finalidades e dos objetivos estabelecidos para essas escolas. Essas instituições prezam pela formação de professores e de estudantes que vise a inovações pedagógicas. O processo educacional realizado nos CAPs, portanto, deve corresponder à excelência esperada e almejada pelos diversos órgãos da educação nacional, sobretudo àquela que cabe à Universidade.

Por muito tempo, a excelência esperada dos CAPs justificava o fato de haver processos de seleção, os chamados exames admissionais, para ingresso nessas escolas. Assim como nas Universidades, o acesso aos Colégios de Aplicação era restrito a fim de manter o padrão educacional elevado e formar uma elite intelectual. Durante muitos anos, então, a matrícula nos CAPs esteve condicionada à aprovação em provas de seleção. A necessidade de realização de provas de ingresso, tais como os vestibulares, acabava por selecionar os indivíduos que poderiam gozar do ensino de qualidade e de excelência desenvolvido nessas escolas. No entanto, num país em que o interesse por expandir o acesso à educação é (ou era) recente, realizar exames que premiariam os melhores candidatos com a aprovação e, por conseguinte, com vagas nos CAPs constituíase como uma forma de perpetuar o modelo educacional elitista do passado.

O fato de alguns CAPs ainda realizarem provas de seleção ou testes de nivelamento leva a crer que, de algum modo, a educação ofertada nessas escolas 
prioriza o acesso das elites. A despeito disso, cabe observar que, na maioria dos CAPs, o sorteio público de vagas é o responsável por selecionar os estudantes que irão ingressar nessas escolas. O sorteio público de ampla concorrência prevê a possibilidade de igualdade de acesso, embora atualmente se tenda a crer que, principalmente por se tratar de uma instituição pública federal, seria mais coerente que se promovesse a equidade, como medida para a superação das profundas desigualdades sociais existentes no país, que tange ao acesso à educação na Universidade.

Assim, ainda que o acesso à Educação Básica na Universidade pública brasileira esteja longe de abranger os estudantes de forma a corresponder às suas expectativas de formação, é possível observar mudanças significativas no modo de se pensar o ingresso nos CAPs, na medida que, por meio da política de cotas e de reserva de vagas, o acesso a essas instituições mostra-se mais diverso e mais democrático.

\section{Considerações finais}

Ao longo da sua história, os CAPs vem sendo pensados e estruturados como instituições destinadas à formação de professores e ao desenvolvimento de práticas pedagógicas inovadoras: inicialmente estabelecidos junto às Faculdades de Filosofia, serviram à prática profissional de estudantes das diferentes Licenciaturas para, com o passar dos anos, dedicarem-se ao ensino, pesquisa e extensão. Sua criação, motivada pelos ideais escolanovistas de educação, faz com que se constituam, e ainda se mantenham, como espaços privilegiados para a experimentação de novas metodologias de ensino. Ou seja, em que pese a crescente aceleração do processo de liberalização da economia e, mais recentemente, o investimento maciço do atual governo na privatização do estado e no desmonte das instituições públicas, em especial, da Universidade, que vem sendo ameaçada, inclusive na sua autonomia, a estrutura dos CAPs ainda pode ser considerada privilegiada em diversos aspectos. Muitas dessas escolas dispõem de um corpo docente compatível com as necessidades educacionais a que se propõe, 
em qualidade e quantidade, e contam com espaços físicos e condições estruturais adequadas ao trabalho pedagógico em diferentes áreas do conhecimento, o que se reflete nos discursos e práticas "de ponta" que nelas se desenvolvem.

O Colégio de Aplicação da UFRGS (CAp/UFRGS), campo empírico da pesquisa que impulsiona o estudo aqui apresentado, por exemplo, desde a sua criação, no ano de 1954, caracteriza-se por possuir, nos seus sucessivos quadros docentes, professores com habilitação específica em Teatro, responsáveis por lecionar e difundir a disciplina como componente curricular, o que, ao longo dos anos, possibilitou a consolidação de uma tradição do ensino de Teatro na instituição escolar.

Na história da escola, destaca-se a atuação da professora Olga Reverbel, expoente da área e figura reconhecida nacionalmente por suas contribuições ao movimento Teatro e Educação ${ }^{8}$, do qual é considerada uma das protagonistas, ao abordar, em sua prática e em suas produções teóricas, as relações entre essas duas áreas do conhecimento (Enciclopédia Itaú Cultural, 2019). Reverbel foi a primeira professora de Teatro do CAp/UFRGS e, ao seu modo, estabeleceu os princípios e métodos para o ensino de Teatro no colégio.

Ao longo do tempo, outras professoras atuaram na instituição e também sugeriram e implantaram diretrizes responsáveis por sucessivas transformações no currículo de Teatro na escola. Tais contribuições refletem-se, de diferentes formas, nas abordagens contemporâneas do ensino de Teatro no CAp/UFRGS, bem como em metodologias e objetivos pedagógicos da área para a formação discente e docente.

\footnotetext{
${ }^{8}$ O termo faz referência ao movimento que objetivou a inserção do ensino de teatro no ambiente educacional, tanto na educação de crianças, jovens e adultos quanto na formação de educadores. De acordo com Koudela e Almeida Junior (2015), outros termos são utilizados para denominar as intersecções das áreas do teatro e da educação, cada um contendo suas particularidades: "teatro na escola", "teatro na educação", "teatro aplicado à educação", "ensino de teatro", "teatro na educação escolar" (Santana, 2010), entre outros. Contemporaneamente, o campo de estudos envolvendo teatro e educação vem sendo vislumbrado pela ótica da Pedagogia do Teatro. Conforme Santana (2012), o termo cunhado por Bertolt Brecht - teórico, diretor de teatro e dramaturgo alemão que concebeu sua teoria da Peça Didática (Koudela; Santana, 2005) - é utilizado internacionalmente e denomina o grupo de pesquisa GT Pedagogia das Artes Cênicas na Associação Brasileira de Pesquisa e Pós-Graduação em Artes Cênicas (ABRACE). De acordo com Koudela e Santana (2005, p.152), a terminologia Pedagogia do Teatro "ncorpora tanto a investigação sobre a teoria e a prática da linguagem artística do teatro quanto sua inserção nos vários níveis e modalidades de ensino".
} 
Atualmente, a instituição conta com seis docentes especialistas em Teatro no seu quadro de professores, o que the possibilita oferecer aulas de Teatro na disciplina de Artes para todos os anos e turmas escolares, do Ensino Regular e da EJA, e oportunizar experiências diversas em relação à prática, à apreciação e à reflexão da arte teatral, configurando uma realidade diferenciada do contexto geral da educação nacional.

No que se refere ao espaço físico adequado às aulas que alguns CAPs dispõem, tomando-se o CAp/UFRGS como exemplo, a estrutura do prédio da escola (sede do colégio desde o ano de 1996), conta com uma ampla sala para as aulas de Teatro. Não é raro ouvir dos alunos da Licenciatura em Teatro da UFRGS (que realizam seus estágios curriculares no colégio), comentários que apontam a superioridade da estrutura do CAp/UFRGS em relação às demais escolas que conhecem, e até mesmo em relação às salas de aula que frequentam no Departamento de Arte Dramática da Universidade. A estrutura para as aulas de teatro no CAp/UFRGS conta também com equipamentos básicos para iluminação, um acervo de figurinos e objetos cênicos e uma pequena biblioteca com obras de autores e dramaturgos teatrais.

Considera-se, assim, que, cursar a Educação Básica e desenvolver o estágio docente em Teatro numa instituição pública com tal estrutura possibilite a realização de trabalhos diferenciados, oportunizando vivências artísticas e reflexivas ampliadas a aprofundadas nesse importante componente curricular.

Nos dias de hoje, como observa Frangella (2000), talvez um dos desafios mais urgentes apresentados aos docentes dos CAPs, seja aliar a reflexão e a pesquisa a respeito do como ensinar à discussão referente a o que ensinar. A destituição do viés elitista da educação e a ampliação do acesso ao conhecimento por todas as parcelas da população passa, necessariamente, pela visão crítico-reflexiva do currículo escolar, o que implica, também, uma profunda revisão das relações de poder/saber entre os diferentes agentes do cotidiano da escola.

Dados da pesquisa que vem sendo realizada a respeito do histórico de ensino de Teatro no CAp/UFRGS indicam que a mudança no público atendido pela escola 
ocasionou certas modificações e adaptações nos conteúdos e noções a serem abordados nas aulas. As narrativas de professoras de Teatro atuantes na instituição entre as décadas de 1970 e 1990 indicam que, se no passado (quando a escola selecionava seus estudantes por mérito), as turmas da escola eram compostas, em sua grande maioria, por crianças e jovens pertencentes a famílias da chamada "elite intelectual" da cidade de Porto Alegre/RS, para quem o acesso à arte e à cultura era mais frequente, ou habitual, as turmas do CAp/UFRGS de hoje (cuja oferta de ingresso é feita mediante sorteio) são desafiadas a conviver com a diversidade de repertório cultural dos seus estudantes. Segundo esses relatos, foi preciso repensar o currículo de Teatro na escola a fim de atender à necessidade de formação teatral para estudantes que, em alguns casos, nunca tinham ido ao teatro 9 .

No dia-a-dia da sala de aula, observa-se que a convivência de estudantes oriundos de diferentes realidades sociais e econômicas, vindos de diversos bairros da cidade e de cidades da Região Metropolitana vem, em maior grau, tornando plural a comunidade escolar. Assim, a ampliação do ingresso de estudantes (pertencentes a diferentes etnias, oriundos de escolas públicas e de famílias de baixa renda e incluindo pessoas com deficiência) ocasiona diversidade, o que, por sua vez, tende a se refletir em transformações curriculares amplas (de relações, de espaço) e estritas (de conteúdos teóricos e práticos). Nesse sentido, nas aulas de Teatro, o professor enfrenta, diariamente, o desafio de levar propostas de atividades e jogos que, em alguma medida, sejam passíveis de transformação e adaptação de acordo com o grupo com o qual trabalha, significando novos desafios às relações entre os sujeitos da sala de aula.

Outro dos desafios que a atual conjuntura impõe aos CAPs é o de expandir a formação de professores para além de seus muros, promovendo intercâmbios com escolas da comunidade, com professores das redes municipais e estaduais, estimulando o contato de estudantes das Licenciaturas com diferentes realidades

${ }^{9}$ Os relatos a que se faz referência têm por base narrativas orais de três professoras de Teatro, colaboradoras da pesquisa (em andamento), convidadas a compartilhar suas experiências docentes à frente da disciplina de Artes-Teatro no CAp/UFRGS, com vistas a compor um panorama sobre o ensino de Teatro na instituição no período compreendido entre os anos de 1954 e 2000. 
de sala de aula. Os CAPs podem e devem usufruir das possibilidades institucionais que dispõem (estrutura física e organizacional das escolas, número de servidores, interação com cursos da Universidade, entre outras), para desenvolverem projetos inovadores em educação com seus estudantes, mas sem perder de vista os vínculos com a pesquisa, que os fundamenta e justifica, e com a extensão, que (consideradas as devidas adaptações às realidades locais) torna suas propostas replicáveis, potencialmente inspiradoras de novos modos de transformar a prática e o pensamento sobre a educação pública na escola.

Para se construir e manter uma sociedade democrática é necessário que uma Educação Básica de qualidade seja extensiva à população de forma geral. Logo, adaptar as formas de acesso e de ingresso aos CAPs adequando-as às políticas de reservas de vagas é atitude indispensável para a promoção da equidade na educação de excelência que se espera dessas escolas. Num momento político complexo, em que a educação pública básica e superior sofrem reiteradas ameaças, conhecer aspectos da história dos CAPs, ressignificando seu papel e suas práticas, pode auxiliar a elaborar estratégias para a ampliação do diálogo entre a Universidade e a Educação Básica e do acesso à educação pública de qualidade à sociedade brasileira.

\section{Referências}

BARCELLOS, Joycimar. Relação escola e religião na década de 30: o impacto do Manifesto dos Pioneiros da Educação Nova. In: XII EDUCERE - Congresso Nacional de Educação, 2015, Curitiba/ PR. Anais do XII EDUCERE. Curitiba/PR: Editora Universitária Champagnat, p. 793-804, 2015.

BENITES, Letícia Neutzling. Colégio de Aplicação da Universidade Federal do Rio Grande do sul e Processos Inclusivos: trajetórias de alunos com necessidades educativas especiais. 2006. 150 f. Dissertação (Mestrado em Educação) Universidade Federal do Rio Grande do Sul, Porto Alegre, 2006.

BRASIL. Decreto-lei no 1.190 de 04 de abril de 1939. Dá organização à Faculdade Nacional de Filosofia. Diário Oficial da União: seção 1, p. 7929, 06 abr. 1939.

BRASIL. Decreto-lei no 9.053, de 12 de março de 1946. Cria um ginásio de aplicação 
nas Faculdades de Filosofia do País. Diário Oficial da União: seção 1, p. 3693, 14 mar. 1946.

BRASIL. Decreto-lei 19.941, de 30 de Abril de 1931. Dispõe sobre a instrução religiosa nos cursos primário, secundário e normal. Diário Oficial da União: seção 1, p. 7191, 06 maio 1931.

BRASIL. Decreto-lei 9.092, de 26 de março de 1946. Amplia o regime didático das faculdades de filosofia, e dá outras providências. Diário Oficial da União: seção 1, p. 4565, 28 mar. 1946.

BRASIL. Ministério da Educação. Manifestos dos pioneiros da Educação Nova (1932) e dos educadores (1959). Fernando de Azevedo... [et al.]. Recife: Fundação Joaquim Nabuco, Editora Massangana, 2010.

BRASIL. Ministério da Educação e do Desporto. Repensando as Escolas de Aplicação: Plano decenal de educação para todos (1993-2003). Brasília, DF, 1993.

BRASIL. Portaria no 959 de 27 de setembro de 2013. Estabelece as diretrizes e normas gerais para o funcionamento dos Colégios de Aplicação vinculados às Universidades Federais. Diário Oficial da União: seção 1, Brasília, DF, n. 189, p. 9, 30 set. 2013.

BOMENY, Helena. Quando os números confirmam impressões: desafios na educação brasileira. Rio de Janeiro: CPDOC, 2003. 29f. Disponível em: <https://cpdoc.fgv.br/producao_intelectual/arq/1354.pdf>. Acesso em: 09 jan. 2020.

CAMPOS, Ernesto de Souza. Colégios de Aplicação. Revista Brasileira de Estudos Pedagógicos. Vol. XXVIII, n. 67, p. 233-240, 1957.

CORREIA, Eveline Soares. Colégios de Aplicação Pedagógica: sua história e seu papel no contexto educacional brasileiro. Rev. Eletrônica Pesquiseduca, v. 09, n.17, jan/abr, p. 116-129, 2017.

FÁVERO, Maria de Lourdes de Albuquerque. A Universidade no Brasil: das origens à Reforma Universitária de 1968. Educar em Revista, v. 1, p. 17-36, 2006.

FRANGELLA, Rita de Cássia Prazeres. Colégio de Aplicação e a instituição de uma nova lógica de formação de professores: um estudo histórico no Colégio de Aplicação da Universidade do Brasil. Anais do / Congresso Brasileiro de História da Educação, 2000, Rio de Janeiro. I Congresso Brasileiro de História da Educação. Rio de Janeiro: Gráfica Scortecci, v. 1, p. 375-376, 2000.

KINPARA, Minoru Martins. Colégio de aplicação e a prática de ensino: questões atuais. 175 f. Dissertação (Mestrado em Educação). Universidade Estadual de Campinas. Campinas: UNICAMP, 1997. 
KOUDELA, Ingrid Dormien (Org.); ALMEIDA JUNIOR, José Simões (Org.). Léxico de Pedagogia do Teatro. São Paulo: Perspectiva: Escola de Teatro, 2015.

KOUDELA, Ingrid Dormien; SANTANA, Arão Nogueira Paranaguá de. Abordagens metodológicas do teatro na educação. Ciências Humanas em Revista, São Luís, v. 3, n.2, p.145-154, dez. $2005 . \quad$ Disponivel em: <http://www.educadores.diaadia.pr.gov.br/arquivos/File/2010/artigos_teses/2010/ Arte/artigos/metodo_teatro.pdf>. Acesso em: 03 mar. 2020.

OLGA REVERBEL. Enciclopédia Itaú Cultural. 2017. Disponível em: <http://enciclopedia.itaucultural.org.br/pessoa513967/olga-reverbel>. Acesso em: 01 set. 2019.

SANTANA, Arão Nogueira Paranaguá de. Os saberes escolares, a experiência estética e a questão da formação docente em artes. Lamparina, Belo Horizonte, v.1, n.1, 2010. Disponível em: <https://www.eba.ufmg.br/lamparina/index.php/revista/article/view/15/6>. Acesso em: 03 mar. 2020.

SANTANA, Arão Nogueira Paranaguá de. Trajetória, avanços e desafios do teatroeducação no Brasil. Sala Preta (USP), São Paulo, v. 2, p. 143-154, 2002. Disponível em: < https://www.revistas.usp.br/salapreta/article/view/57098/60086>. Acesso em: 03 mar. 2020.

SANTOS, Vera Lúcia Bertoni dos. Possibilidades e desafios da iniciação à docência em teatro na Educação Básica. Urdimento, v.1, n.18, p.77-83, $2012 a$.

SANTOS, Vera Lúcia Bertoni dos. Shakespeare enfarinhado: estudos sobre teatro, jogo e aprendizagem. São Paulo: Hucitec, 2012b.

SILVA, Tomaz Tadeu da. Documentos de identidade: uma introdução às teorias do currículo. Belo Horizonte: Autêntica Editora, 2015.

Recebido em: 23/03/2020

Aprovado em: 16/05/2020 